\title{
Morphological Distinction Between Different H Serotypes of Escherichia coli
}

\author{
By A. M. LAWN* \\ Lister Institute of Preventive Medicine, London $S W_{\mathrm{I}} W 8 R H$ \\ AND I. ØRSKOV AND F. ØRSKOV \\ Collaborative Centre for Reference and Research on \\ Escherichia coli $(W H O)$, Copenhagen, Denmark
}

(Received 9 February 1977)

\begin{abstract}
The structure of the flagellar filaments of 50 Escherichia coli strains, each with a different $\mathbf{H}$ antigen, was examined. Although the flagella within each strain were structurally identical, there was variability in flagellar surface pattern between strains with different $\mathrm{H}$ antigens. Investigation of additional strains confirmed that flagella structure was the same in all strains having the same $\mathrm{H}$ antigen. In three pairs of strains with cross-reacting $\mathrm{H}$ antigens, the antigenic relatedness was associated with identical flagella structure.
\end{abstract}

\section{INTRODUCTION}

Although the serological reactions of the flagella of Escherichia coli are used to distinguish between different strains ( $H$ serotypes), there have been few reports on the ultrastructure of these flagella. An examination of the flagellar filaments of different $\mathrm{H}$ serotypes of $E$. coli revealed a surprising degree of variability in their ultrastructure. This paper describes the different types of surface structure that could be recognized and the connexion between structure and $\mathrm{H}$ serotyping. The potential value of these morphological differences for distinguishing between strains of $E$. coli is discussed. A brief account of the results of this investigation has been published (Lawn, Ørskov \& Ørskov, 1975).

\section{METHODS}

All the strains of $E$. coli were from the collection of the Collaborative Centre for Reference and Research on Escherichia coli (WHO), Copenhagen. The primary investigation was of the internationally recognized standard reference strains used in $\mathrm{H}$ serotype identification (see Table $\mathrm{I}$ ). The strains were routinely grown in Oxoid nutrient broth no. 2. When necessary the strain was passaged through Craigie tubes, containing a motility medium with a gelatin and agar basis, until the majority of the bacteria were flagellated in samples examined in the electron microscope.

Before they were prepared for electron microscopy the bacteria were usually fixed with either formalin $(0.5$ to $1.0 \%, \mathrm{v} / \mathrm{v})$ or glutaraldehyde $(\mathrm{I} \cdot 0$ to $2.5 \%, \mathrm{w} / \mathrm{v})$ by the addition of either formalin $(37 \%$ to $40 \%$ formaldehyde gas) or a $25 \%$ solution of glutaraldehyde directly to the cultures. Fixation times varied between 0.5 and $24 \mathrm{~h}$ or longer.

The bacteria were washed and transferred to specimen grids using a modification of the membrane filter technique described by Lawn \& Meynell (1970). The grids were covered with a carbon-coated formvar membrane and were subjected to ionic bombardment to ensure a hydrophilic surface which promoted even distribution of the bacteria and of the negative-contrast agent, which was a solution of uranyl acetate. The technical difficulties that were experienced in obtaining adequate demonstration of the surface pattern of bacterial flagella are described with the results.

* Present address: Houghton Poultry Research Station, Houghton, Huntingdon, Cambridgeshire PEI 7 2DA. 


\title{
Table I. Assignment of the flagella of different $H$ serotypes of Escherichia coli to morphotypes
}

\begin{abstract}
A to $\mathrm{F}$ represent the principal morphotypes which include two or more serotypes with flagella of similar surface structure (see Fig. I and Table 2). The flagella of serotypes labelled U have a unique type of surface structure not readily grouped with those of any other serotype.
\end{abstract}

\begin{tabular}{|c|c|c|c|c|c|}
\hline H serotype & $\begin{array}{c}\text { Standard reference } \\
\text { strain }\end{array}$ & Morphotype & H serotype & $\begin{array}{c}\text { Standard reference } \\
\text { strain }\end{array}$ & Morphotype \\
\hline I & SuI 242 & E & 28 & N87 & $\mathrm{F}$ \\
\hline 2 & ві7455-4I & $\mathrm{C}$ & 29 & $\mathrm{~N} 282$ & $\mathrm{C}$ \\
\hline 3 & ві7327-4I & U & 30 & NI57 & $\mathrm{F}$ \\
\hline 4 & U9-4I & A & $3 \mathrm{I}$ & KIS & $\mathrm{F}$ \\
\hline 5 & U4-4I & B & 32 & $26 \mathrm{w}$ & $F$ \\
\hline 6 & A20a & F & 33 & $\mathrm{KI} 8 \mathrm{I}$ & B \\
\hline 7 & U5-4I & $\mathrm{E}$ & 34 & BPI 2665 & $\mathrm{E}$ \\
\hline 8 & AP32OC & D & 35 & $4370-53$ & $\mathrm{U}$ \\
\hline 9 & ві7575-4I & $U$ & 36 & $5017-53$ & $\mathrm{U}$ \\
\hline IO & ві623-42 & $\mathrm{C}$ & 37 & PIIa & $\mathrm{F}$ \\
\hline II & Su432I-4I & $\mathrm{D}$ & 38 & P9b & B \\
\hline 12 & вi3 I 6-42 & $\mathrm{E}$ & 39 & E3a & B \\
\hline 14 & FIOOI 8-4I & $F$ & 40 & E49 & $\mathrm{D}$ \\
\hline 15 & E39a & $\mathrm{F}$ & $4 \mathrm{I}$ & $\operatorname{RVCI} 787$ & $\mathrm{~F}$ \\
\hline 16 & F83 I 6-4I & $\mathrm{U}$ & 42 & $\mathrm{PgC}$ & B \\
\hline 17 & PI $2 b$ & A & 43 & $I 49-5 I$ & $C$ \\
\hline I 8 & $\mathrm{KI} 2 \mathrm{a}$ & F & 44 & $78 \mathrm{I}-55$ & $F$ \\
\hline I9 & AI $8 d$ & $\mathrm{~F}$ & 45 & $4106-54$ & $\mathrm{E}$ \\
\hline 20 & $\mathrm{H} 33 \mathrm{Ob}$ & $\mathrm{F}$ & 46 & $5306-56$ & $\mathbf{F}$ \\
\hline $2 I$ & UI Ia-44 & D & 47 & $1755-58$ & B \\
\hline 23 & $\mathrm{~K} 42$ & $\mathrm{E}$ & 48 & P4 & $\mathrm{C}$ \\
\hline 24 & $\mathrm{~K} 72$ & $\mathrm{C}$ & 49 & $2147-59$ & $\mathrm{E}$ \\
\hline 25 & N234 & B & $5 \mathrm{I}$ & C218-70 & $\mathrm{E}$ \\
\hline 26 & $\$ 239$ & F & 52 & $C 2187-69$ & B \\
\hline 27 & K50 & D & 53 & E480-68 & $\mathrm{C}$ \\
\hline
\end{tabular}

\section{RESULTS}

\section{Preservation of surface detail}

It must be emphasized that the flagella of $E$. coli are, in general, so labile to acid $\mathrm{pH}$ that the uranyl acetate solution used as a negative-contrast agent rapidly disintegrated them. In portions of the preparation where there were pools of uranyl acetate, and in which drying was presumably retarded, unfixed flagella were usually dissociated into clouds of protein particles which could not be resolved. These clouds had no distinct outline, but often followed a sinusoidal path associated at one extremity with a flagellar root. Flagella of some serotypes were made considerably more resistant to acid by fixation in 0.5 to $\mathrm{I} \cdot 0 \%$ formalin for one or more hours. However, the flagella of other serotypes became swollen and lost their characteristic surface pattern as a result of contact with uranyl acetate even after fixation with $2.5 \%$ glutaraldehyde for I week, although the flagella retained a distinct outline under these circumstances.

Unfortunately none of the conventional neutral solutions used as negative-contrast agents gave results comparable with the high-contrast, detailed surface structure revealed by uranyl acetate under ideal conditions. Formalin fixation was used for the results reported here unless otherwise stated. The best preparations were obtained with a relatively dilute solution of uranyl acetate (about $0.5 \%$ ) which was rapidly removed immediately after its application. Specimen grids with a hydrophilic surface were essential. Even in these preparations satisfactory micrographs were obtained only from limited areas of the grid, where conditions were near to ideal. 


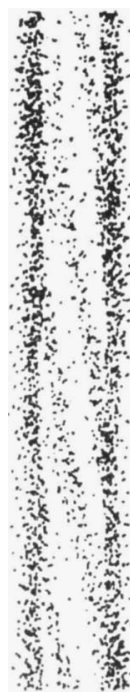

A

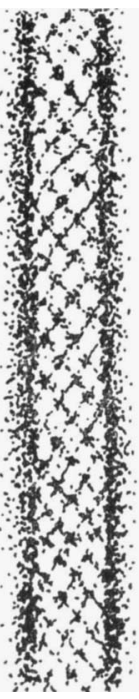

B

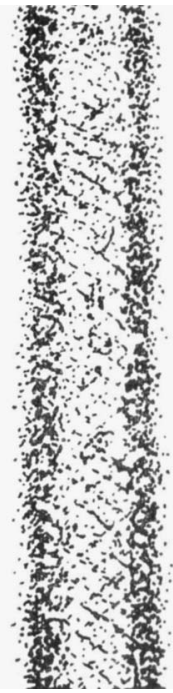

C

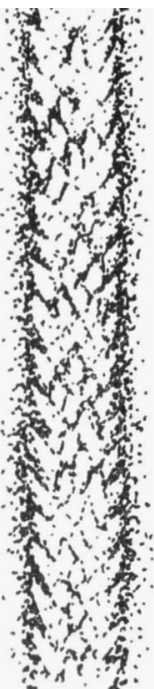

$\mathrm{D}$

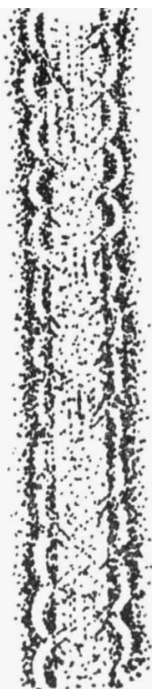

E

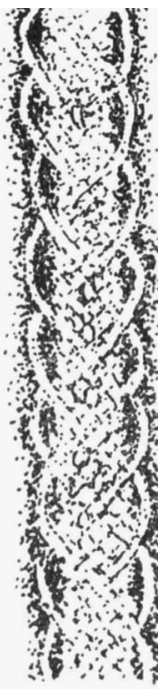

$\mathrm{F}$

Fig. I. Diagrams representing the surface structure of the six principal morphotypes.

Table 2. Some properties of flagella of the principal morphotypes and of serotypes $\mathrm{H}_{9}$ and $\mathrm{H}_{3} 6$ of Escherichia coli

The third column gives the number of $\mathrm{H}$ serotypes having flagella with the type of structure characteristic of the morphotype indicated in columns $\mathbf{I}$ and 2 . The diameters are only approximate and include the full extent of any regular projections from the flagellum; they were measured from flagella of the given representative strain. The molecular weights of flagellin obtained from flagella of the representative strains were determined by SDS-polyacrylamide gel electrophoresis (Lawn, I977).

\section{Morpho- type}

A

B

C

D

E

F
Description of morphotype

Thin, long pitch helix pattern

Thin, subunit pattern

Rough subunit pattern

Polar subunit pattern

Short pitch loop pattern

Long pitch loop pattern

Unique pattern

Unique pattern

$\begin{array}{cccc}\begin{array}{c}\text { No. of } \\ \text { serotypes }\end{array} & \begin{array}{c}\text { Representative } \\ \text { serotype }\end{array} & \begin{array}{c}\text { Diam. of } \\ \text { flagella (nm) }\end{array} & \begin{array}{c}\text { Mol. wt of } \\ \text { flagellin }\end{array} \\ 2 & \text { H4 } & \text { I9 } & 37000 \\ 8 & \text { H5 } & 20 & 46000 \\ 7 & \text { H48 } & 23 & - \\ 5 & \text { H2I } & 22 & 56000 \\ 8 & \text { H12 } & 22 & 62000 \\ \text { I5 } & \text { H46 } & 24 & 56000 \\ \text { I } & \text { H9 } & 27 & 69000 \\ \text { I } & \text { H36 } & 25 & 61000\end{array}$

\section{Flagellar morphotypes}

Under satisfactory conditions of negative contrast, the filaments of the flagella in a pure culture of $E$. coli from a single serotype all possessed the same surface structure. The flagella of any one serotype, however, often showed easily recognized differences from those of another, although in some instances the flagella of two different $\mathbf{H}$ serotypes were indistinguishable from each other. Differences in overall diameter and in surface structure were recorded.

Thus the flagella of different strains of $E$. coli could be grouped according to their structure; these groups will be called flagellar morphotypes. Those morphotypes to which two or more serotypes can be assigned will be called the principal morphotypes. They are represented diagrammatically in Fig. $I$ and are described in the following paragraphs and in Table 2. 

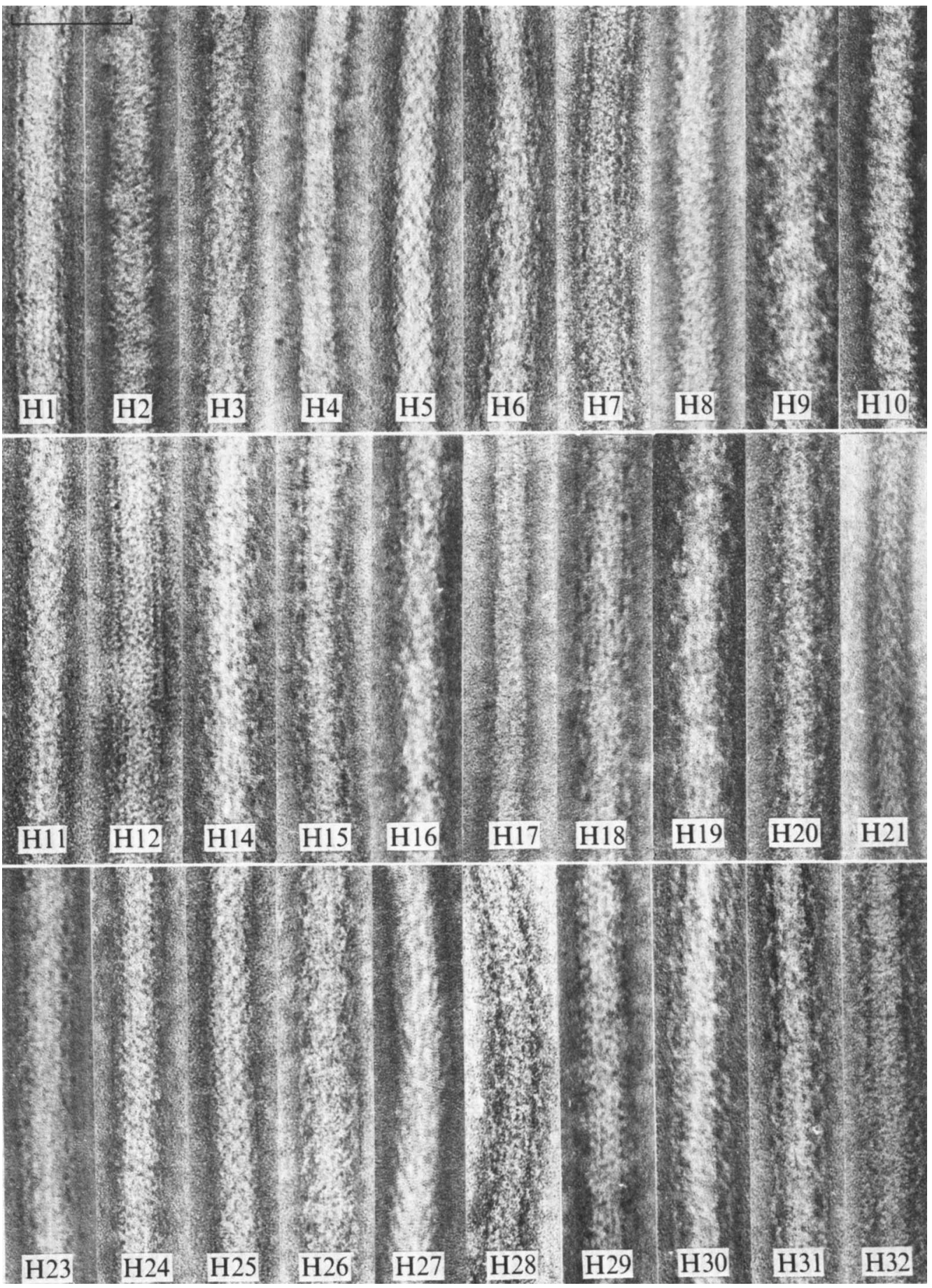

Fig. 2. Surface structure of the flagellar filaments of Escherichia coli serotypes $\mathrm{H}_{\mathrm{I}}$ to $\mathrm{H}_{53}$. Preparations were fixed with formalin and negatively stained with uranyl acetate except that for $\mathrm{H}_{2}, 10,24$, $26,29,34,37,43$, and 48 , preparations were fixed with glutaraldehyde because this gave better definition of the surface structure. [H/3 and $\mathrm{H}_{22}$ were removed from the Escherichia antigen scheme when it was discovered that they were Citrobacter strains, and $\mathrm{H}_{5} \mathrm{O}$ has recently been withdrawn as an $\mathrm{H}$ antigen.] The assignment to morphotypes given in Table 2 was based on a large sample of flagellar filaments of each strain. Bar markers represent $50 \mathrm{~nm}$. 


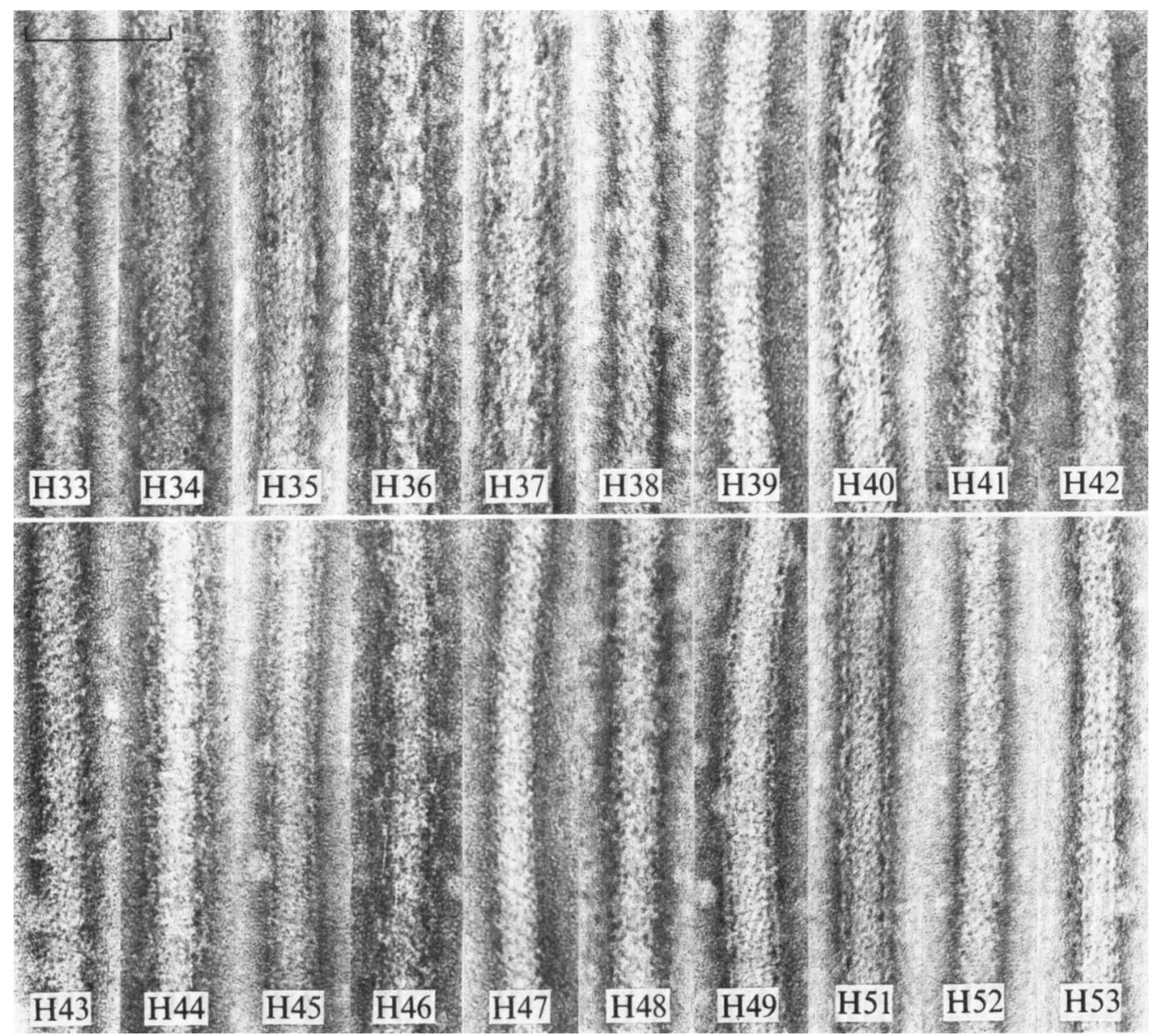

Fig. 2 (continued). For legend see opposite.

Table I lists all the known $E$. coli $\mathrm{H}$ serotypes and indicates which of them can be assigned to the six principal morphotypes. Figure 2 illustrates the flagellar morphology of $50 \mathrm{H}$ serotypes.

Morphotype A. Thin flagella with a surface pattern suggesting near-longitudinal helical grooves. These flagella were thin and had a smooth, rather featureless surface with little evidence of the apparent subunits characteristic of the much studied flagella of Salmonella typhimurium (see Smith \& Koffler, I97I). Their most prominent feature was the presence of a series of helical, almost longitudinal, grooves which modulated the profile of the flagellum so that it appeared to vary in diameter periodically along its length. Only two serotypes, $\mathrm{H}_{4}$ and $\mathrm{I}_{7}$, could be assigned to this morphotype.

Morphotype B. Thin flagella with a surface pattern suggesting subunits. These thin flagella had a prominent surface pattern of diagonal striations suggesting the presence of subunits arranged in a helical manner. The markings were better defined than those of the flagella of $S$. typhimurium and the edges of the flagellum had a sharply outlined profile. Eight serotypes, $\mathrm{H}_{5}, 25,33,38,39,42,47$ and 52 , could be included in this group. The flagella of $\mathrm{H}_{5}$ and $\mathrm{H} 25$ closely resembled each other and had the best defined surface features, while the remaining serotypes appeared more heterogeneous and had less sharply defined profiles; they sometimes slightly resembled morphotype $C$. These minor variations need confirmation because they could be technical artefacts. 
Morphotype $C$. Flagella with an ill-defined rough surface suggesting subunits. These flagella, like those of morphotype $\mathrm{B}$, had diagonal striations suggesting the presence of subunits, but the striations were not as prominent, and the profile of the flagellum was irregular and ill-defined. Near-longitudinal striations were sometimes observed. When glutaraldehyde was substituted for formalin as a fixative, the surface was more sharply defined but still irregular. Seven serotypes, H2, IO, 24, 29, 43, 48 and 53, could be included in this group. The $E$. coli strain $\mathrm{KI} 2$, much used in genetic experiments, has flagella of $\mathrm{H}_{4} 8$ serotype which is of this morphotype. The resemblance between the flagella of morphotypes C and D and the flagella of $S$. typhimurium was stronger than between flagella of other serotypes of $E$. coli and those of Salmonella.

Morphotype D. Flagella with a polar subunit pattern. Although these flagella superficially resembled those assigned to morphotype $\mathrm{C}$, closer examination revealed that their profile was serrated, with the points of the serrations all inclined towards one pole of the flagellum. Diagonal striations were most prominent but discontinuous near-longitudinal striations were sometimes visible. Fragments of flagella of this type were particularly likely to exhibit differences between their two extremities as described for Salmonella (Poglazov, 1966; Asakura, Eguchi \& Iino, I968); one end was pointed and the other (the end to which the points were directed) was forked. The flagella of this morphotype formed a relatively uniform group to which five serotypes could be assigned, H8, II, 2I, 27 and 40, although the flagella of $\mathrm{H}_{40}$ showed some resemblance to morphotype C. Like morphotype $\mathrm{C}$, flagella of this morphotype had features in common with those of $S$. typhimurium.

Morphotype E. Flagella having looped edges suggesting a helical sheath, Io $\mathrm{nm}$ edge repeat (short pitch loop). These flagella, like those of morphotype F, had a gap filled with the contrast agent between the surface layer and the central core of the flagellum. The surface layer at the edge appeared as loops which sometimes seemed to connect with diagonal striations across the surface of the flagellum, suggesting the presence of sheath-like helical strands wound around it. The distance between successive loops at one edge was approximately Io $\mathrm{nm}$. The loops varied in prominence periodically along the length of the flagellum. This type frequently associated to form arrays of flagella in close contact so that the two sets of surface loops between neighbouring flagella appeared as a pair of continuous lines. Eight serotypes could be assigned to this group, $\mathrm{Hr}, 7, \mathrm{I} 2,23,34,45,49$ and $5 \mathrm{I}$. However, the flagella of $\mathrm{H}_{34}$ were more sensitive to acid than those of the other serotypes and required fixation with glutaraldehyde before the looped structure could be recognized.

Morphotype F. Flagella having looped edges suggesting a helical sheath, $20 \mathrm{~nm}$ edge repeat (long pitch loop). These flagella were similar to those in morphotype $\mathrm{E}$ in that they appeared to have a covering of sheath-like helical strands, but the distance between successive loops at one edge was approximately $20 \mathrm{~nm}$. The gap filled with contrast agent between the surface layer and the core was wider and less sharply outlined in comparison with the corresponding region of morphotype $\mathrm{E}$ and there appeared to be more variation in detail between flagella of different serotypes having this same general structure. These flagella did not readily form arrays in close contact with each other, and they were sometimes separated by a constant gap. The loops seen at each edge did not vary in prominence along the flagellum. Fifteen serotypes could be assigned to this morphotype, H6, I4, I5, I8, I9, 20, 26, 28,3 0, 3I, 32, 37, $4 \mathrm{I}, 44$ and 46. The flagella of $\mathrm{H}_{2} 6, \mathrm{H}_{3} 7$ and $\mathrm{H}_{4} \mathrm{I}$ were more sensitive to acid than the others and required glutaraldehyde fixation before the looped structure could be recognized.

Serotypes with unique morphology. The remaining serotypes each had flagella which did not sufficiently resemble those of any other serotype to be grouped with them. There was some resemblance between the flagella of $\mathrm{H}_{3}$ and $\mathrm{H}_{1} 6$, both having prominent diagonal striations but no distinct subunit-like pattern. The flagella of $\mathrm{H}_{3} 6$ (Fig. 2, Table 2) were easily recognized because, although they also had diagonal striations, they were thicker than the flagella of $\mathrm{H}_{3}$ or $\mathrm{H}_{1} 6$ and gave the appearance of a stranded rope. There was a slight resemblance between these flagella and the types possessing external loops, particu- 

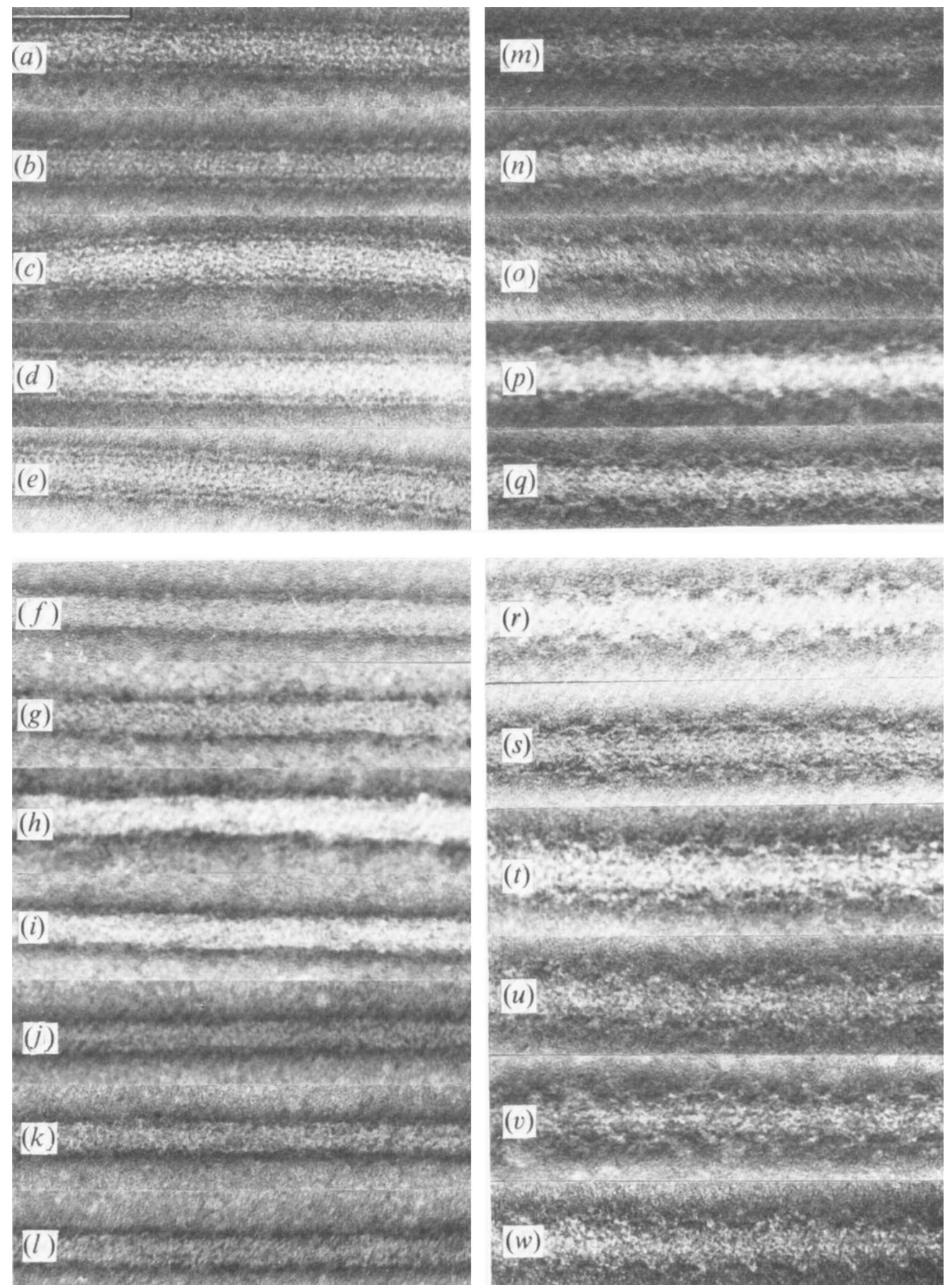

Fig. 3. Comparison of the surface structure of flagellar filaments from different isolates of Escherichia coli of the same $\mathrm{H}$ serotype. Figures $(a)-(e)$ are flagella of serotype $\mathrm{HI} 2$, the strains being: (a) 5306-56; (b) H5I9; (c) E47a; (d) Bi316-42 (type strain); (e) PIOa. Figures $(f)$ - $(l)$ are flagella of serotype $\mathrm{H}_{4}$, the strains being: $(f)$ 30w; $(g)$ G3404-4I ; $(h)$ Pus3432-4I ; $(i) 2 \mathrm{I} 60-43 ;(j)$ H3I6; $(k)$ E68; $(l)$ RVC2907. Figures $(m)-(q)$ are flagella of serotype HI9, the strains being: $(m)$ P6a; $(n)$ H709c; (o) $\mathrm{H} 36$; $(p)$ AI $8 \mathrm{~d}$ (type strain); $(q) \mathrm{F} 9095-4 \mathrm{I}$. Figures $(r)-(w)$ are flagella of serotype $\mathrm{H} 9$, the strains being: $(r)$ Bi7575-4I (type strain); $(s)$ AI69a; $(t)$ A502a; $(u)$ 4866-53; $(v)$ EI 529-68; $(w)$ A29Oa. All the flagella were fixed with glutaraldehyde except those of serotype Hi2 for which formalin gave better definition of the surface structure. Although $\mathrm{H}_{9}$ flagella resemble $\mathrm{Hig}$ flagella, they are thicker. Bar marker represents $50 \mathrm{~nm}$. 
larly when the contrast agent was thinly distributed. The flagella of $\mathrm{H}_{9}$ serotype (Fig. 2, Table 2) were exceptionally thick and were also extremely sensitive to acid dissociation. When fixed with glutaraldehyde there were suggestions of peripheral loops with a resemblance to flagella of morphotype $F$ with which they shared a similar $20 \mathrm{~nm}$ edge repeat. The flagella of serotype $\mathrm{H}_{35}$ had features in common with those of morphotype $\mathrm{E}$ but they were thinner and the looped surface layer was more intimately associated with the core.

\section{Comparison between the structure of flagella of different isolates of $E$. coli having the same $H$ serotype}

Four $\mathrm{H}$ serotypes were chosen which possessed flagella with easily identified and characteristic surface patterns. For each serotype a number of different strains (see legend to Fig. 3) were selected from the collection of the Collaborative Centre for Reference and Research on Escherichia coli, most of them being standard $\mathrm{K}$ or $\mathrm{O}$ antigen reference strains. The morphology of the flagella of each strain was compared with that of the flagella of the standard reference strain of the appropriate $\mathrm{H}$ serotype. The strains comprised seven of serotype $\mathrm{H}_{4}$ (morphotype A), six of serotype $\mathrm{H}_{9}$ (unique morphology but exceptionally wide), five of serotype Hi2 (morphotype E) and five of serotype Hig (morphotype F). In every case, with satisfactory staining conditions, the surface pattern of the flagella of strains of the same $\mathrm{H}$ serotype resembled each other morphologically but were easily distinguished from those of strains from the other serotypes (Fig. 3).

\section{Relationship between serological cross-reactions of flagella and their surface structure}

The diversity of surface structure of the flagella of different $\mathrm{H}$ serotypes of $E$. coli was first noticed when we examined three pairs of cross-reacting serotypes. HI cross-reacted with $\mathrm{H}_{1} 2, \mathrm{H}_{4}$ with $\mathrm{H}_{1} 7$ and $\mathrm{H}_{1}$ I with $\mathrm{H}_{2} \mathrm{I}$ but there were no cross-reactions between these pairs (I. Ørskov and F. Ørskov, unpublished observations). The presence or absence of specific cross-reactions between the serotypes was confirmed by the direct observation of antibody binding to flagella using the electron microscope (Lawn, 1967). When the structure of these flagella was examined it was discovered that in each case the flagella of crossreacting serotypes were morphologically indistinguishable from each other, but were easily distinguished from those of the immunologically distinct serotypes.

\section{DISCUSSION}

It is surprising to find such great morphological variation between flagella of different strains of the genus Escherichia; the differences are as great as those reported between widely different families of bacteria (Smith \& Koffler, 197I). These differences may have escaped attention previously because the frequently used laboratory strain, $\mathrm{KI}_{2}$, is of $\mathrm{H}_{4} 8$ serotype which has a conventional, Salmonella-like surface structure; this is not the case for flagella of most $E$. coli serotypes. The observed differences in diameter and surface structure are accompanied by considerable differences in the molecular weight of the polypeptide, flagellin, from which the flagella are assembled (Lawn, 1977). Flagella of $E$. coli do not show the variation with phase typical of Salmonella and genetic experiments are compatible with the presence of a single structural gene (Ørskov \& Ørskov, 1962; Mäkelä, 1964). Although most investigations of the ultrastructure of the flagella of Salmonella have employed S. typhimurium (see Smith \& Koffler, I97I, for a review; O'Brien \& Bennett, 1972), flagella of one phase of Salmonella abortusequi have also been examined in the electron microscope by Asakura et al. (1968) and Barden \& Diebel (1972) examined a number of Salmonella species but found no major variations in surface structure between the flagella of different phases and species. Pseudomonas rhodos produces two types of flagella, one of which has a sheath-like surface (Schmitt, Raska \& Mayer, 1974). 
Because flagella are so susceptible to acid dissociation, the use of uranyl acetate as a contrast agent poses its own problems. The surface structure revealed using aldehyde fixation followed by negative contrast with uranyl acetate may not be exactly that present in the normal flagellum but partly an effect of the acid $\mathrm{pH}$ and the reaction with a charged, heavy metal-containing ion. Nevertheless, the regularity of the structure and its reproducibility in different isolates having the same $\mathrm{H}$ serotype amply demonstrate the usefulness of this technique. It provides a rapid method for differentiating between motile $E$. coli isolates, but not, of course, with the precision of serological methods. The finding that serotypes which do not cross-react may have flagella which are morphologically similar may be useful in defining evolutionary relationships between $E$. coli strains.

We have found that in some instances serological $\mathrm{H}$ cross-reaction between serotypes and morphological resemblance between their flagella are associated, but the tests involved a small sample of the $\mathrm{H}$ cross-reactions that have been reported (see Edwards \& Ewing, 1972) some of which are between serotypes belonging to very different morphotypes. The ubiquitous presence of common pili (fimbriae) in E. coli may conceivably explain some of these unexpected cross-reactions which need to be confirmed as true flagellar antigen reactions, using electron microscopy serology, before the connexion between morphology and serology of $E$. coli flagella can be properly defined.

Characteristic appearances similar to those of morphotypes $\mathrm{E}$ and $\mathrm{F}$ have, in other genera of enterobacteria, been attributed to the presence of a separate sheath assembled over a conventional core (Lowy \& Hanson, 1965; Schmitt et al., 1974). Evidence that this is not the case for the $E$. coli flagella described here is given by Lawn (1977).

The flagella of morphotype $C$ possess what appears to be a poorly organized surface. Although this may be due to the presence of a part of the polypeptide chain which is more randomly arranged than in the other morphotypes, this appearance could also result from the failure of glutaraldehyde fixation to prevent denaturation by uranyl acetate, even when fixation is prolonged.

A. M. Lawn is grateful to Ivor Osborne for his excellent technical assistance.

\section{REFEREN CES}

Asakura, S., Eguchi, G. \& Iino, T. (I968). Unidirectional growth of Salmonella flagella in vitro. Journal of Molecular Biology 35, 227-236.

Barden, N. T. \& DeIBel, R. H. (1972). Flagellar cross-repolymerization among different Salmonella serotypes and Escherichia coli. Journal of Bacteriology I12, 637-639.

EdWARds, P. R. \& EWING, W. H. (1972). Identification of Enterobacteriaceae, $3 \mathrm{rd}$ edn. Minneapolis: Burgess Publishing Co.

LAWN, A. M. (1967). Simple immunological labelling method for electron microscopy and its application to the study of filamentous appendages of bacteria. Nature, London 214, I I 5 I-II 52.

LAwN, A. M. (1977). Comparison of the flagellins from different flagellar morphotypes of Escherichia coli. Journal of General Microbiology ror, I 2 I-I30.

LaWn, A. M. \& Meynell, E. (1970). Serotypes of sex pili. Journal of Hygiene 68, 683-694.

LAWN, A. M., ØRSKov, I. \& ØRSKOV, F. (1975). Morphological distinction between the flagella of different H serotypes of Escherichia coli. Proceedings of the Society for General Microbiology 2, 65.
Lowy, J. \& Hanson, J. (1965). Electron microscope studies of bacterial flagella. Journal of Molecular Biology II, 293-313.

MÄKelÄ, P. H. (I964). Genetic homologies between flagella antigens of Escherichia coli and Salmonella abony. Journal of General Microbiology 35, 503510.

O'Brien, E. J. \& Bennett, P. M. (1972). Structure of straight flagella from a mutant Salmonella. Journal of Molecular Biology 70, 133-152.

Ørskov, F. \& ØRSKOV, I. (1962). Behaviour of Escherichia coli antigens in sexual recombination. Acta pathologica et microbiologica scandinavica 55, 99-109.

Poglazov, B. F. (1966). Structure and Functions of Contractile Proteins. New York: Academic Press.

SCHMitT, R., RASKA, I. \& MAYER, F. (I974). Plain and complex flagella of Pseudomonas rhodos: analysis of fine structure and composition. Journal of Bacteriology I17, 844-857.

Smith, R. W. \& KoffleR, H. (I97I). Bacterial flagella. In Advances in Microbial Physiology, vol. 6, pp. 219-339. Edited by A. H. Rose and J. F. Wilkinson. London: Academic Press. 